\title{
The Smart Grid using in the Kuzbass open-pit coalmine
}

\author{
Irina Semykina ${ }^{1, *}$ Andrey Evstratov ${ }^{1}$, and Gennady Lebedev $^{2}$ \\ ${ }^{1}$ T.F. Gorbachev Kuzbass State Technical University, Department of Electric Drive and Automation, \\ 650000, 28 Vesennyaya Street, Kemerovo, Russia \\ ${ }^{2}$ T.F. Gorbachev Kuzbass State Technical University, Department of Mining and Power Industries, \\ 650000, 28 Vesennyaya Street, Kemerovo, Russia
}

\begin{abstract}
The Smart Grid system become to apply all over the world. It provides significant efficiency increasing of power supply networks by supporting its balanced load. The key design features of each Smart Grid system depend on individual characteristics of particular power supply network which are determined by the structure of its electrical energy consumers. Relating to Kuzbass open-pit coalmines it is necessary to take into account the nonstationarity of its power supply scheme, the strict requirements of power supply reliability and the high capacity of consumers. This article is connected with the "Kedrovskiy" open-pit coalmine and describes its power supply scheme and the structure of its consumers. The downtimes and electrical equipment failures are analyzed and the connection between the number of emergency downtime and the number of working excavators is found out. The load of "Kedrovskiy" power distribution network is calculated for the strip mining operation. The results show power distribution network under consideration does not provide the effectiveness functioning and the implementation of Smart Grid is a good decision. There are the structure and design calculation of proposed Smart Grid in the article. It is finally depicted that Smart Grid" system decreases the downtimes of electric equipment and increases the power supply reliability.
\end{abstract}

\section{Introduction}

An electrical grid is a complicated system that consists of wires and transmission towers, cables, transformers and breakers, which are interconnected some way with each other and with electrical energy consumers. Traditionally power distribution network is supplied from a limited number of power supply sources, which are heat power station or diesel power station, but now power distribution network has tended to become a decentralized bidirectional intelligent grid of consumers and different kind of supply sources including renewable energy generation. Such distribution network is called Smart Grid [1].

Smart Grid system increases the power supply reliability due to automated analytics and raised controllability and observability of electric power grid. Smart Grid

\footnotetext{
* Corresponding author: siyu.eav@kuzstu.ru
} 
controllability leads to not only raising of its efficiency but to decreasing of social environmental impact thank for using clean, renewable sources of energy like solar, wind and geothermal [2]. Implementation of Smart Grid, especially on high-voltage and heavily loaded power distribution network, demands new types of equipment, for example, alternating current to direct current interconnections or point-topoint bulk power transmission [3]. Some solutions were tried out in such a big project as UK's North Wes or Turkish Kayseri ve Civarı Elektrik Türk A.Ş. [4] or Sub-Saharan Africa [5].

Some category of electrical energy consumers has the special aspects of the power supply. For example, the above mentioned is intended to describe an open-pit coalmine. Modern coalmines are almost completely mechanized and the operations involve a set of technics specified to open-pit mines so that smart technology is going to interpenetrate there [6].

Mining machines like rope shovels and dragline are in need of power supply with a high capacity and according to the producing method, they may produce an increased load during critical periods. The average weekly load profile of any open-pit coalmine tell as the plant is not producing at full capacity which implies either maintenance is being carried out on the plant modules or it is stopped. The plant completely stops on some periods, thus resulting in a much lower baseload compared to when the plant is not producing at full capacity. The load is torn between 10th and 90th percentile that is a significant variation [7]. That is why it is important to apply the Smart Grid to open-pit coalmine, especially if the power system becomes more decentralized with higher renewable energy penetration to balance the grid.

Smart Grid also can report power usage across all of the consumers and its sensors on remote areas cause warning signs to flash at the central control center when problems arise. It has to be noted that miners already produce huge amounts of sensor data, potentially enabling them to implement in the Smart Grid. In additional, intelligent algorithms can be used to predict consumers cut out. Moreover, complex mining tasks such as geological modeling, on-the-day scheduling, and predictive maintenance are increasingly in the domain of smart statistical and optimization algorithms in Smart Grid [8]. Taking into consideration the open-pit coalmine specific, communication between sensors and control center may be organized with wireless technology [9]. Another part of Smart Grid system for open-pit coalmine may become the generators that use kinetic energy from transported gangue material [10] or supercapacitor for use in the rope shovels [11].

With a glance to all of the aforesaid, the main task in the creation of Smart Grid system for open-pit coalmine is an analysis of its consumer's structure and searching of Smart Grid system itself. So the aim of the research is an investigation of one of the open-pit coalmine supplied from the National Grid and a proposition of its Smart Grid.

\section{Subject of research}

According to the aim of research let us consider «Kedrovskiy» that is one of Kuzbass openpit coalmine. The «Kedrovskiy» power supply has the combined scheme with $6 \mathrm{kV}$ portable transmission lines that are direct-axis on the open-pit embankments and cross-axis at the embankments crossing. The main electrical energy consumers are excavators. They are connected to portable transmission lines by switching substations equipped with pressure vacuum breakers. The excavator's supply system has the isolated neutral. The number of connected excavators does not exceed the allowance which is specified by mining technology $[12,13]$. The auxiliary electrical energy consumers are supplied by portable package transformer substations with $0.38 \mathrm{kV}$ or $380 / 220 \mathrm{~V}$ voltage level and with 
solidly grounded neutral. These transformer substations have an overcurrent protection and short-circuit protection. It must be truth not only for Russia but for another country [14]

The «Kedrovskiy» emergency downtime book and electrical equipment failure book for the year 2014 got to the bottom based on which the paired regression analysis and the correlation analysis of power supply reliability were carried out. In the analysis, the influence of each factor was looked separately. The result is the multiple regression model:

$$
N=23.2+7.39 L_{p}+24.55 N_{e}+1.99 N_{a},
$$

where $N$ - the number of emergency downtime, $L_{p}$ - the length of portable transmission lines, $N_{e}$ - the number of connected excavators, $N_{a}$ - the number of auxiliary electrical energy consumers.

The next step of research was multiple regression model verification. For that, the $F$-test was carried out. This test includes a comparison of determination coefficient $R^{2}$ with the critical value, which is determined by table [15], corresponded to the referred confidence level. If $R^{2}$ is less than the critical value then the multiple regression model is not verified and if not the model can be used.

In this research, the confident level was fixed at $5 \%$ so the critical value of $R^{2}$ was 0.764 . The obtained $R^{2}$ was 0.882 that means the multiple regression model of power supply reliability is verified. In the case of «Kedrovskiy», it goes to show the number of emergency downtime is mostly affected by the number of connected excavators.

\section{Investigation of power distribution network}

The next research stage was the investigation of power distribution network supplied the excavators. Let us consider Fig. 1 that show the part of distribution network with two excavators and the decontamination station.

The load calculation for this electric scheme was carried out for the overburden-mining regime with specific energy consumption method. In the calculation, recommendations from handbook [16] were taken into account. The scheme load parameters are presented in Table 1.

The power distribution network under consideration was analyzed at the maximum load by computer simulation. The simulation model in relation to Fig. 1 contains the models of drive motors for «ESH 13/50» excavator, which is dragline, and for «EKG-10» excavator, which is rope shovel, the switching equipment models, and the distributed-parameters cable models.

Table 1. The parameter of «Kedrovskiy» load.

\begin{tabular}{|c|c|c|c|}
\hline \multicolumn{3}{|c|}{ Parameter } & Value \\
\hline \multicolumn{3}{|c|}{ Voltage, kV } & 6 \\
\hline \multicolumn{3}{|c|}{ Simultaneously operating consumers power, kW } & 17854 \\
\hline \multicolumn{3}{|c|}{ Equipment shift-working factor } & 0.85 \\
\hline \multicolumn{3}{|c|}{ Demand factor } & 0.53 \\
\hline \multirow{2}{*}{\multicolumn{2}{|c|}{ Power factor }} & $\cos \varphi$ & 0.99 \\
\hline & & $\operatorname{tg} \varphi$ & 0.14 \\
\hline \multirow{4}{*}{$\begin{array}{c}\text { Estimated } \\
\text { maximum load }\end{array}$} & \multicolumn{2}{|c|}{ active, $\mathrm{kW}$} & 9535 \\
\hline & \multirow{2}{*}{ reactive, $\mathrm{kVAr}$} & lagging & 1356 \\
\hline & & leading & - \\
\hline & \multicolumn{2}{|c|}{ full-power, kVA } & 9631 \\
\hline
\end{tabular}




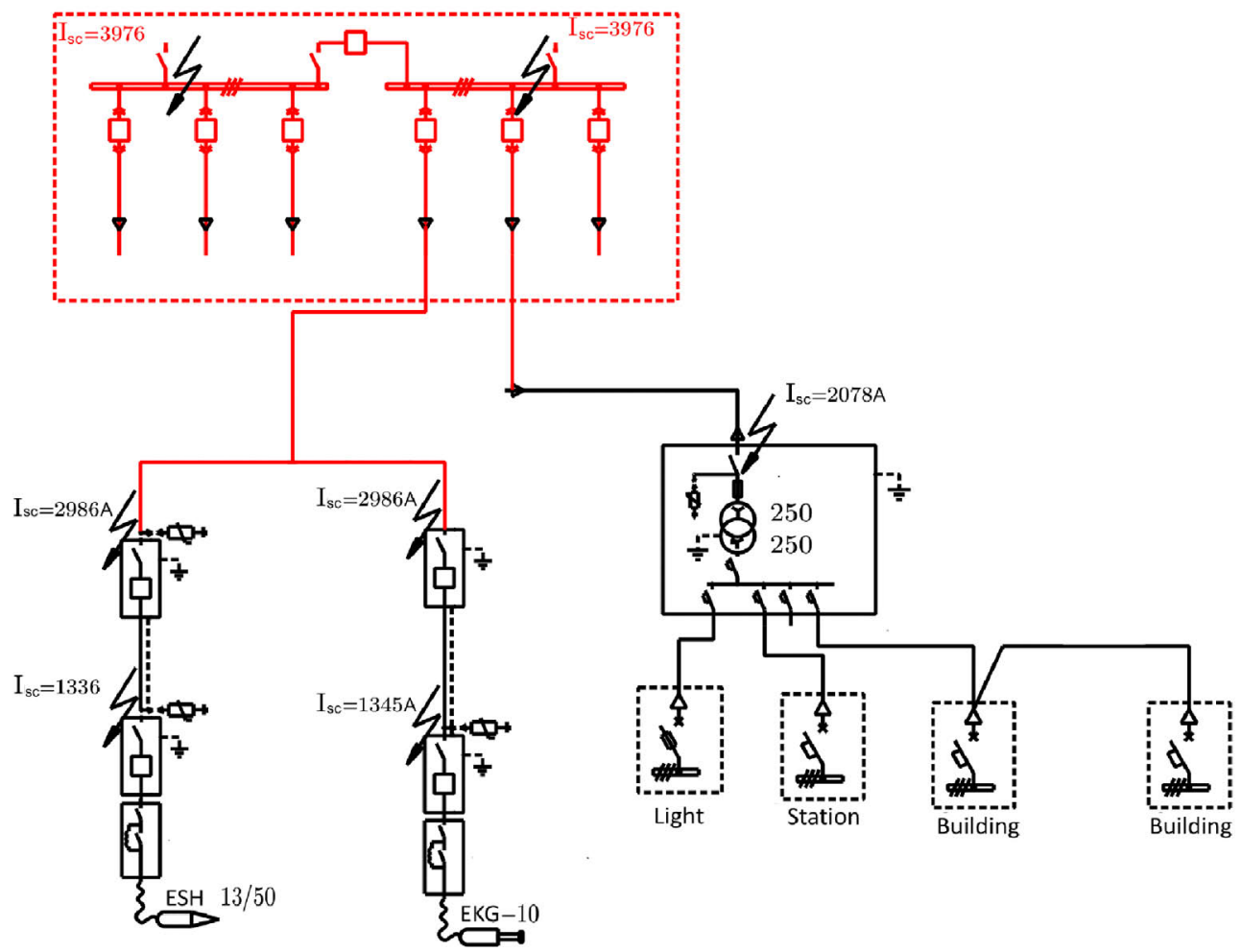

Fig. 1. The part of «Kedrovskiy» distribution network

Simulation results are shown in Fig. 2 where we can see the voltage at the excavator's motor terminal is 2.36 times smaller than the feeder voltage. It testifies the excavators cannot starting up because of this low voltage level leads to activation of the sustained start protection. All similar evidence have to be noted down at «Kedrovskiy» emergency downtime book.

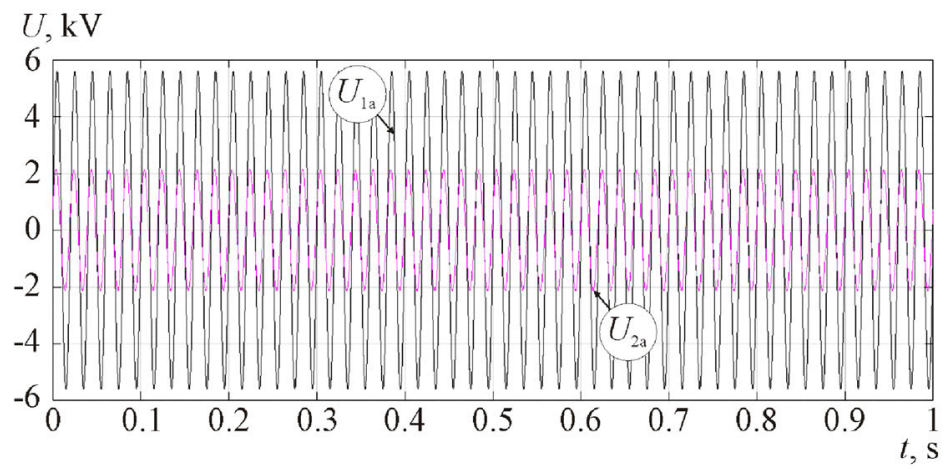

Fig. 2. The line-to-neutral voltage at the simultaneous starting-up of both excavators: $U_{1 \mathrm{a}}-$ the feeder phase voltage; $U_{2 \mathrm{a}}-$ the motor terminal phase voltage for «EKG-10» excavator.

The above mentioned confirms «Kedrovskiy» power distribution network does not provide all the way functioning of main open-pit coalmine equipment at the maximum load and coupled with the absence of a bright-line rule for auxiliary equipment using at peak usage times, this power distribution network need to modernization. The effective solution is the Smart Grid. 


\section{Analysis of Smart Grid and conclusion}

The proposed Smart Grid system make compensation of voltage level at excavator starting up by using of accumulators and grid-controlled inverters with a capacity equal $40 \%$ of startup power consumption total for all excavator's motor in the considered power distribution network. This Smart Grid system was simulated with discussed simulation model. The obtained result is presented in Fig. 3.

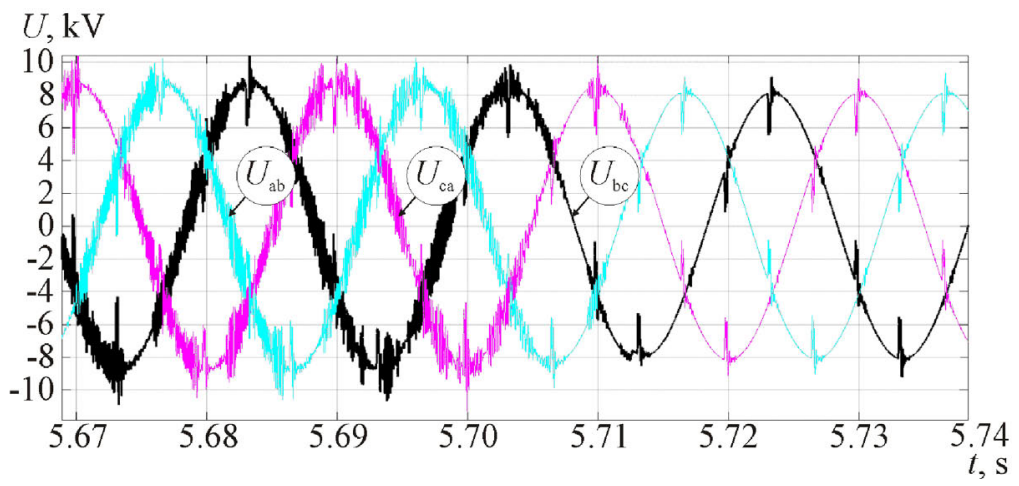

Fig. 3. The motor terminal line-to-line voltages for «EKG-10» excavator at the simultaneous startingup of both excavators with Smart Grid.

Despite high-frequency harmonics, the voltage characteristics provide evidence the proposed Smart Grid system ensures power supply in «Kedrovskiy» power distribution network at the maximum load with high quality. In addition, it allows controlling of auxiliary equipment and provides it's using only at minimal load. So, Smart Grid system decreases the downtime of electric equipment and increases the power supply reliability thereby the open-pit coalmine partly becomes the self-supporting object.

Regardless of Smart Grid using requires high investment cost to reconstruction the power distribution network and it is too expensive to implement it at «Kedrovskiy», it should be noted Smart Grid system will be effective at the newly built Kuzbass open-pit coalmine.

\section{References}

1. C.W. Gellings The Smart Grid: Enabling Energy Efficiency and Demand Response (The Fairmont Press, 2009)

2. The Smart Grid: an introduction, prepared for the U.S. Department of Energy by Litos Strategic Communication (2008)

3. M. Claus, D. Retzmann1, D. Sörangr, K. Uecker, 17th Conference of the Electric Power Supply Industry (Siemens AG, 2008)

4. Geospatial World, 5, 16 (2015)

5. Donald I. Bleiwas Estimates of Electricity Requirements for the Recovery of Mineral Commodities, with Examples Applied to Sub-Saharan Africa (USGS National Minerals, 2011)

6. 100 Innovations in the Mining Industry (The Mining Association of Canada, 2012)

7. Coenraad Benjamin Pretorius Development of a Demand Response Programme for the Coal Mining Industry (Stellenbosch University, 2016) 
8. Mining's next performance horizon: Capturing productivity gains from innovation, Metals and Mining (McKinsey \& Company, September 2015)

9. Wireless communications for open-pit fleet management, Network. The newsletter of ABB's Network Management business unit, 3 (2014)

10. S.A. Linkov et al., Procedia Engineering, 129 (2015)

11. Babak Parkhideh, Subhashish Bhattacharya, Joy Mazumdar, Walter Koellner, IEEE Industry Applications Society Annual Meeting (2008)

12. William A. Hustrulid, Mark Kuchta, Randall K. Martin Open Pit Mine Planning and Design, 1308 (CRC Press, 2013)

13. Kshirod Chandra Brahma A Study on Application of Strategic Planning Models and Operations Research Techniques in Opencast Mining (The National Institute of Technology, Rourkela, 2007)

14. Electrical Protection and Earthing, Mine Safety Operations EESO05 (NSW DPI Technical Reference, 2006)

15. Scott H. Irwin The Multiple Regression Model: Joint Hypothesis Testing (University of Illinois, 2006)

16. R.J. Thompson Surface Strip Coal Mining Handbook (South African Colliery Managers Association, 2005) 